\title{
SISTEM PERINGATAN DINI KETAHANAN PANGAN DAERAH: PENATALAKSANAAN DAN PELIBATAN SELURUH PEMANGKU KEPENTINGAN 1
}

\author{
Lukman Hakim \\ Yosafat Hermawan Trinugraha \\ Pusat Informasi Pembangunan Wilayah (PIPW) LPPM UNS Solo \\ Jawa Tengah, Indonesia; Email: lukkim@gmail.com \\ Mulyanto \\ Hery Sulistyo JNS \\ Badan Pusat Statistik (BPS) Solo \\ Bambang Nugraha \\ Suryono \\ Bank Indonesia (BI) Solo
}

\begin{abstract}
Early Warning System (EWS) is a solution of food security of the most important in the management of the policy (Governance) food security. This study departs from best practices (best practices) in the regional autonomy that has been applied in the area surrounding the Surakarta and management of food security that is initiated by Bank Indonesia (BI) and the Central Statistics Agency (BPS) through Regional Inflation Control Team (TPID). This study uses FGD and AHP method are used to build the index of food security EWS. The results of this study indicate that areas that do not have high production in food commodities indeed have a higher susceptibility than having high production.
\end{abstract}

Key words: Food security, Inflation

\section{PENDAHULUAN}

Detahanan pangan menjadi fokus kebijakan pembangunan sektor pertanian sejak kebijakan revolusi hijau diperkenalkan. Secara umum, ketahanan pangan mencakup ketersediaan pangan dalam

\footnotetext{
${ }^{1}$ Didanai oleh DIPA Skema Penelitian Unggulan PT Tahun 2012.

QE Journal | Vol.03 - No.02 June 2014 - 68
} 
jumlah cukup yang dikonsumsi penduduk baik di level global, nasional, sampai dengan rumah tangga (Pinstrup-Andersen, 2009). Selain Food and Agriculture Organization (FAO) yang telah mengembangkannya, konsep ketahanan pangan juga diintegrasikan sebagai pendekatan teknis dalam upaya pencapaian Tujuan-tujuan Pembangunan Milenium (Millennium Development Goals-MDGs). Melalui upaya pengarusutamaan MDGs oleh Perserikatan Bangsa-bangsa (PBB) di negara berkembang, kemudian telah menempatkan pemerintah sebagai implementor utama konsep ini.

Dengan melekatnya tanggung jawab ketahanan pangan kepada pemerintah, berimplikasi terhadap peran pemerintah sebagai jangkar efektifitas palaksanaan konsep ini. Meskipun demikian, sampai dengan saat ini studi di bidang ini masih terbatas fokusnya pada penggunaan kerangka analisis permintaan (demand) dan penawaran (supply) pangan. Di sisi lain, hal ini justru menyebabkan pembahasan ketahanan pangan belum menangkap isu penting yakni tentang penatalaksaanaan (governance) dari ketahananan pangan. Beberapa ahli menegaskan bahwa penatalaksanaan atau tata kelola (governance) selain menjadi paradigma baru juga menjadi determinan penting dalam efektifitas ketahanan pangan teramsuk dalam model analisis ketahanan pangan (Timmer, 2004ab; Falcon \& Naylor \& 2005. Shaw, 2007; Guha-Khasnobis, 2007; Behnassi et, al 2011)

Bagi Indonesia isu penatalaksanaan kebijakan ketahanan pangan bukan masalah baru. Sejak Orde Baru peran Badan Urusan Logisitik (Bulog) merupakan representasi negara sebagai solusi penanganan masalah ketidaktahanan pangan (food insecurity). Situasi di akhir era Orde Lama yang ditandai oleh kelangkaan dan hiperinflasi harga kebutuhan pokok dapat diatasi berkat eksistensi Bulog (Ali, et, al 1996). Lembaga ini telah berhasil menjadi solusi dalam mengatasi kerawanan pangan selama hampir tiga dekade hingga berakhirnya Pemerintahan Soeharto. Bahkan Timmer et al (1983) menjadikan Bulog sebagai salah satu bentuk praktekpraktek terbaik (best practices) dalam mengelola ketahanan pangan suatu negara dan menjadi proyek percontohan di berbagai negara lain.

Namun situasi itu berubah seiring dengan jatuhnya Pemerintahan Soeharto, Bulog yang pada masa Orde Baru langsung di bawah Presiden, pada era reformasi harus berubah menjadi Perusahaan Umum (Perum) dengan kewenangan yang sangat terbatas dalam mengamankan pangan. Keterbatasan Bulog antara lain ditunjukkan oleh fakta saat ini lembaga ini

QE Journal | Vol.03 - No.02 June 2014 - 69 
harnya berhak mengendalikan komoditas beras saja. Hal ini berbeda dibandingkan sebelumnya, Bulog tidak hanya mengelola beras namun sejumlah komoditi kebutuhan pokok yang lain seperti gula, garam, minyak goreng. Dalam mengendalikan komoditas-komoditas pangan tersebut, Bulog berwenang langsung melakukan operasi pasar, jika terjadi kelangkan pangan.

Perubahan kelembagaan negara terutama sejak otonomi daerah membuat peran Bulog dalam mengelola ketahanan pangan berbeda dibandingkan sebelumnya. Bulog tidak bisa langsung melakukan operasi pasar, tanpa ada persetujuan Pemerintah Kota/Kabupaten. Ssaat ini, kewenangan tersebut berada di Pemerintah Kota/Kabupaten. Inilah aspek krusial dalam pengelolaan ketahanan pangan pada masa reformasi ini, apalagi ketika sebagian besar kebutuhan pokok tidak dapat dikendalikan oleh negara, melainkan justru oleh kekuatan pasar, namun peran organ negara seperti Bulog tidak memiliki payung hukum untuk melakukannya. Bahkan saat ini tantangan utama pengelolaan ketahanan pangan adalah volatilitas harga kebutuhan pokok yang sangat fluktuatif dan sulit dikendalikan (Naylor \& Falcon, 2011; Timmer, 2011). Volatilitas ini yang mempengaruhi kualitas akses masyarakat terhadap pangan (Eide, 2007).

Ini yang menyebabkan terjadinya sengkarut kewenangan antara pemerintah pusat dan daerah serta Bulog sebagai BUMN dalam memperkuat ketahanan pangan. Beberapa prakarsa muncul untuk mengatasi masalah ini salah satunya justru diprakarsai oleh Bank Indonesia (BI) yang bekerjasama dengan Badan Pusat Statistik (BPS). Prakarsa ini bermula dari upaya kedua lembaga itu untuk memantau fluktuasi harga barang kebutuhan pokok yang memang sangat volatile termasuk berusaha mengidentifikasi faktor yang menjadi determinannya. Setelah diketahui penyebab dari kenaikan harga, kemudian mereka mengumpulkan Satuan Kerja Pemerintah Daerah (SKPD), Bulog dan aparat kepolisian untuk melakukan upaya pengendalaian melalui pemantauan bersama. Upaya tersebut diformalkan melalui pembentukkan Tim Pengendali Inflasi Daerah (TPID). Salah satu TPID yang telah berfungsi secara efektif ada di Kota Solo. Saat ini, TPID Kota Solo telah menjadi contoh baik (best practices) untuk diterapkan di beberapa kota yang lain.

QE Journal | Vol.03 - No.02 June 2014 - 70 
Dengan demikian, di wilayah Solo dan sekitarnya dewasa ini indikasi ketidaktahanan pangan dapat terdeteksi sehingga dapat dengan mudah diatasi oleh pihak yang berwenang. Kajian yang dilakukan oleh Hakim, et al (2010) menunjukkan bahwa TPID di Kota Solo telah bekerja secara efektif dalam mengendalikan harga barang melalui pengurangan kesenjangan informasi yang tidak semetris (assymetric information). Lebih lanjut, studi ini mengidentifikasi hal tersebut sebagai bagian upaya memperkuat ketahanan pangan di daearah. Dalam perspektif kelembagaan, TPID dapat menjadi alternatif sengkarut kewenangan antara pemerintah pusat, pemerintah daerah serta Bulog dalam menjaga ketahanan pangan di seluruh Indonesia. Meskipun demikian, dalam implementasi penatalaksanaannya, TPID masih harus didukung oleh instrumen yang dapat memberikan indikasi awal dalam mengambil keputusan yang tepat untuk menjaga ketahanan pangan daerah.

Dalam studi yang dilakukan sebelumnya menunjukkan pentingnya memiliki instrumen yang mampu memberikan informasi akan aspek-aspek penyokong ketahanan pangan dalam menjaga ketahanan pangan di daerah (Hakim et.al, 2010). Untuk kepentingan itu, instrumen Sistem Peringatan Dini (early warning system) ketahanan pangan merupakan solusi tepat dalam penatalaksanaan (governance) kebijakan ketahanan pangan khususnya di daerah. Studi ini menjadi solusi alternative untuk mengisi kesenjangan tersebut.

Berdasarkan latar belakang di atas, secara umum penelitian ini akan mengembangkan Sistem Peringatan Dini Ketahanan Pangan yang dapat digunakan secara operasional seluruh pemangku kepentingan (stakeholders) seperti Bank Indonesia, BPS, Bulog, Pemkot, Kepolisian dan pihak terkait lainnya yang saat ini telah bergabung dalam Tim Pengendali Inflasi Daerah (TPID) di Wilayah Eks Karesidenan Surakarta.

Pokok-pokok esai yang ditulis Malthus merupakan referensi utama terhadap pandangan penyediaan pangan yang memadai untuk memenuhi kebutuhan manusia. Dalam tulisannya yang berjudul An Essay on the Principle of Population, Malthus (1798) mendasarkan bukti empiris menunjukkan bahwa perkembangan populasi lebih cepat dibandingkan dengan perkembangan produksi pangan. 
The natural inequality of two powers of population and of production in the earth, and that great law of our nature which must constantly keep their effects equal, form the great difficulty that to me appears insurmountable in the way to the perfectibility of society....

Perluasan konsep ketahanan pangan tidak dapat dilepaskan dari dinamika perekonomian global dan perdagangan bebas, sehingga pendekatan penyediaan pangan melalui produksi dan stok untuk menjaga ketahanan pangan tidak lagi memadai. Di sisi lain, pergeseran sektor ekonomi ke sektor industri membuat negara berkembang termasuk Indonesian hambatan dalam meningkatkan produksi pangannya. Saat ini negara berkembang seperti Indonesia menghadapi tantangan yang kompleks. Beberapa tantangan seperti stagnasi produktivitas pangan untuk memenuhi kebutuhan pangan termasuk sekatan efisiensi perdagangan dan distribusi pangan dalam menjamin aksesibilitas pangan (Arifin, 2007).

Konsep ini terinspirasi oleh Sen (1981) melalui bukunya Poverty and Famine. Sen mengenalkan konsep ini setelah mengamati paradoks bahwa kelaparan di India terjadi justru di daerah yang berlimpah pangan. Melalui pengamatan ini, Sen (1981) mengkritik simplifikasi teori Malthus tentang pemenuhan kebutuhan pangan penduduk. Dalam konsepnya Sen mengenalkan bahwa aksesibilitas masyarakat terhadap pangan tidak berdiri sendiri, namun merupakan aspek yang terintegrasi secara politik, ekonomi dengan institusi maupun lembaga lain.

\section{Konsep Ketahanan Pangan}

The World Food Summit (1996) memberi cakupan ketahanan pangan yaitu suatu kondisi dimana semua orang, setiap waktu, mempunyai akses fisik. sosial dan ekonomi terhadap bahan pangan yang aman dan bergizi, guna memenuhi kebutuhan tubuh untuk hidup aktif dan sehat (Hariyadi dan Andarwulan. 2003). Lebih lanjut, Khudori (2004) membedakan ketahanan pangan menjadi empat pilar yaitu ketersediaan pangan. stabilitas ketersediaan pangan. aksesibilitas ketersediaan pangan serta konsumsi dan utilisasi makanan hasil pangan. Berdasarkan kerangka FIVIMS atau Food Insecurity and Vulnerability Information and Mapping System ketersediaan pangan yang di masa lalu dikenal dengan swasembada pangan hanya merupakan salah satu aspek ketahanan pangan. Seluruh aspek dalam sistem ketahanan pangan memiliki tujuan utama yang tidak sebatas 
mencegah kelaparan namun dititik beratkan pada aspek pemenuhan gizi masyarakat. Oleh karena itu, jika kasus gizi buruk terjadi di beberapa daerah di Indonesia. hal tersebut menunjukkan bahwa tidak terjaminnya sistem ketahanan pangan di Indonesia sesuai amanat UU No.7/1996 tentang pangan.

Berbeda dengan rezim orde baru yang memfokuskan kebijakan ketahanan pangan pada sektor produksi, saat ini langkah pemerintah untuk menjaga ketahanan pangan adalah kebijakan penganekaragaman pangan. Krishnamurti (2003) menegaskan bahhwa penganekargaman pangan menjadi salah satu unsur pokok dalam konsumsi pangan yang cukup mutu dan gizinya. Lebih lanjut, fakta menunjukkan bahwa usaha penganekaragaman pangan di Indonesia bukan merupakan hal yang baru. Hal tersebut ditunjukkan oleh kebijakan pembentukkan Panitia Perbaikan Makanan Rakyat (1950-an). Usaha Perbaikan Gizi Keluarga (1963). Inpres 14/1974 tentang Perbaikan Menu Makanan Rakyat (PMMR). di akhir Pelita VI dikembangkan Program Diversifikasi Pangan dan Gizi (DPG) (Krishnamurti, 2003).

Ketercakupan model terhadap indikator yang menunjang model ketahanan merupakan isu lain dari pendekatan-pendekatan model ketahanan pangan. Dengan mempertimbangkan kedua isu tersebut, Fangquan (2002) menggunakan pendekatan alternatif dalam pemodelan ketahanan pangan melalui penggunaan indeks. Penggunaan indeks mampu mengatasi permasalahan pertama khususnya dalam standardisasi ukuran variabel yang digunakan sebagai indikator dalam mengukur ketahanan pangan.

\section{Standar Pelayanan Minimum Ketahanan Pangan}

Seperti standar pelayanan minimum bidang kesehatan dan pendidikan, Standar Pelayanan Minimum Ketahanan Pangan (SPM KP) diamanatkan melalui Peraturan Menteri Pertanian. SPM ketahanan pangan disusun oleh empat pilar utama yaitu bidang ketersediaan dan cadanga pangan, a) Bidang ketersediaan dan cadangan pangan; b) Bidang Distribusi dan akses pangan; c) penganekaragaman dan keamanan pangan; d) Bidang penanganan kerawanan pangan. SPM-KP ini memberi landasan kepada pemerintah daerah untuk dapat mengelola pangan dengan tujuan dasar untuk memenuhi kecukupan pangan bagi masyarakat. Tingkat pemerintah 
daerah yang melakukan pengelolaan terhadap pangan ini adalah pemerintah provinsi dan pemerintah kabupaten (Khudori, 2004).

\section{Ketahanan Pangan Model TPID}

Indonesia pernah mengalami situasi hiperinflasi yang berat baik yang disebabkan oleh faktor permintaan (demand) maupun penawaran (supply). Pengalaman hiperinflasi pertama sebagai akibat faktor permintaan (demand side inflation) di mulai pada masa Kabinet Hatta (20 Desember 1949-6 September 1950) yang disebabkan oleh meningkatnya jumlah uang beredar. Untuk mengatasi inflasi itu, pada tanggal 19 Maret 1950, Menteri Keuangan Sjafruddin Prawiranegara mengumumkan kebijakan "pengguntingan uang" yang juga dikenal sebagai "gunting Sjafruddin", terhadap uang NICA. Untuk mencegah efek negatif dari tindakan ini, maka separuh mata uang dipakai sebagai alat pembayaran, dan separuh lainnya ditukar dengan surat obligasi pemerintah yang dibayar kembali secara berangsur-angsur (Prawiranegara, 1987).

Tentu saja, mengingat tingkat inflasi dan tingginya peredaran uang, tindakan ini secara ekonomis bisa dibenarkan, dan pada waktu yang bersamaan, pengguntingan uang ini juga bernapaskan semangat nasionalisme. Setidak-tidaknya, kenyataan ini tercermin dari pernyataan Sjafruddin Prawiranegara (1987:102): “We had to get a uniform currency for the whole of Indonesia".

Adanya Tim Pengendali Inflasi Daerah (TPID) yang dibentuk atas prakarsa Bank Indonesia dan disyahkan oleh Pemerintah Kab/kota menjadi sangat penting. Karena pengendi inflasi tidak dimonopoli oleh satu lembaga saja, tetapi menjadi tanggung jawab semua stakeholders di daerah yang meliputi antara lain Pemkab/kota, Bank Indonesia, BPS, Kepolisian, dan Bulog. TPID pada prinsipnya adalah memantau inflasi, sekaligus mengurangi adanya distorsi harga sebagai akibat adanya informasi yang tidak simetris tentang perkembangan harga. Dengan informasi yang relatif simetris akan dapat mereduksi etimasi masyarakat yang berlebihan tentang kemungkinan adanya kekurangan pasok sebuah komoditi yang dapat memicu adanya inflasi yang tinggi. Dengan demikian dengan adanya TPID membantu masyarakat agar meyakini adanya kepastian pasokan dan harga komoditi barang-barang kebutuhan pokok. (selengkapnya lihat Hakim, et al (2010)).

QE Journal | Vol.03 - No.02 June 2014 - 74 


\section{METODE PENELITIAN}

\section{Kerangka Penelitian}

Penelitian ini merupakan penelitian multidimensi yang melibatkan pendekatan ekonomi dan sosiologi. Pendekatan itu diilhami oleh Gunnar Myrdal (1968).

Penggabungan metode ini dirasakan perlu dalam membedah masalah ketahanan pangan, karena adanya sebuah kesadaran baru bahwa ketahanan pangan bukan hanya persoalan ekonomi namun mempunyai spektrum yang lebih luas seperti sosial, budaya dan politik (Denzin dan Lincoln, 1994). Berdasarkan hal itu, studi akan menggunakan pendekatan kuantitatif dan kualitatif. Pendekatan kuantitatif diwujudkan dengan analisis data primer dan sekunder yang diwujudkan dalam bentuk indeks dan menggunakan metode AHP. Sementara pendekatan kualitatif melalui wawancara mendalam (in-deph interviewing) dan juga Focus Group Discussion (FGD).

\section{Focus Group Discussion (FGD)}

FGD adalah forum diskusi yang terfokus atau terarah. Bertujuan untuk mengelaborasi pendapat dari para pemangku kepentingan dalam satu masalah tertentu. Jadi yang hadir dalam FGD adalah mereka yang benarbenar dianggap paham tentang masalah yang dihadapi (Irwanto, 2006).

Untuk dapat menggali masalah secara lebih komprehensif, biasanya seorang diperlukan seorang fasilitator dengan ketrampilan khusus antara lain seni bertanya, teknis menggali lebih dalam (probing), dan seni membuat ikhtisar (parafrase) (LGSP, 2008).

\section{Analytical Hierarchy Process (AHP)}

AHP dipergunakan untuk melakukan penilaian faktor-faktor kualitatif yang dikemukakan secara subyektif. Penilaian ini diberikan dengan membandingkan antar elemen. Perbandingan tersebut dilakukan dengan memberikan skor. Misalnya, perbandingan antara faktor sistem finansial dan sistem politik dalam konteks efektivitas sistem pengawasan. Apabila responden memberi skor 4 (empat) untuk sistem finansial dibanding sistem politik, maka nilai untuk sistem politik dibanding sistem finansial adalah 1/4. Metode ini digunakan karena salah satu aksioma AHP adalah reciprocal comparison. Dengan demikian, apabila responden sudah

$$
\text { QE Journal | Vol.03 - No.02 June } 2014 \text { - } 75
$$


memberikan skor 4, dia tidak perlu lagi mengisi skor $1 / 4$ sebagai kebalikannya.

Skoring yang digunakan adalah skala 1-9 dengan pengertian sebagai berikut:

Skor 1 : sama-sama penting (equal importance)

Skor 3 : lumayan penting (moderate importance)

Skor 5 : lebih penting (strong importance)

Skor 7 : sangat penting (very strong importance)

Skor 9 : sangat dan sangat penting (extreme importance)

Skor 2,4,6,8 adalah skor pertengahan nilai atas dan bawah

Penilaian dilakukan oleh para ahli, melalui lembar kuiesioner. Setelah itu akan dicari nilai rata-rata dari penilaian terpisah tersebut, dengan rumus:

$$
A w=\frac{n}{\sqrt{a_{1} \cdot a_{2} \ldots a_{n}}}
$$

Dengan, $A w$ adalah Rata-rata ukur, $a_{i}$ adalah penilaian dari responden ke-i, dan $n$ adalah jumlah responden.

Dalam konteks ini, AHP memberikan toleransi inkonsistensi sebesar $10 \%$. Inkonsistensi akan ditemukan dengan cara sebagai berikut:

$\mathrm{C}_{1} \ldots \mathrm{C}_{\mathrm{n}}=$ level dalam hirarki, $\mathrm{W}_{1} \ldots \mathrm{W}_{\mathrm{n}}=$ bobot pengaruh, $\mathrm{a}_{\mathrm{ij}}=$ angka yang menunjukkan kekuatan $C_{1}$ jika dibandingkan dengan $C_{j}$.

Matriks resiprokalnya adalah: $\mathrm{A}=\left(\mathrm{a}_{\mathrm{ij}}\right) ; \mathrm{Uji}=1 / \mathrm{a}_{\mathrm{ij}}$

Matrik A konsisten jika:

$$
a_{i j} \cdot a_{j k}=a_{i k} ; a_{i k} \cdot a_{k j}=a_{i j} ; a_{i j} \cdot a_{k i}=a_{j i}
$$

Cara lain untuk mengetahui inkonsistensi adalah dengan menyusun rasio inkonsistensi menggunakan rumus berikut.

$$
\mathrm{RK}=\mathrm{IK} / \mathrm{IR}
$$

Dengan $\mathrm{RK}=$ Rasio konsistensi, IK = indeks konsistensi, IR = indeks random.

Cara mencari indeks konsistensi dengan rumus sebagai berikut:

$$
\mathrm{IK}=(\lambda \text { maks }-\mathrm{n}) /(\mathrm{n}-1)
$$


Indeks Random adalah :

Uk. Matrik 345678910

Indeks Random $\quad 0,58 \quad 0,90 \quad 1,12 \quad 1,24 \quad 1,32 \quad 1,41 \quad 1,45 \quad 1,49$

Dalam pembahasan selanjutnya pencarian konsistensi akan menggunakan rasio konsistensi karena lebih akurat. Dengan menggunakan software SuperDecisions seperti yang dipakai dalam analisis ini, semua parameter yang diperlukan sudah ditampilkan.

\section{Index}

Indeks merupakan pendekatan yang sederhana (parsimony) dalam menggambarkan suatu kondisi statis pada waktu tertentu dalam suatu kerangka indeks tertentu. Evaluasi terhadap kerangka model ketahanan pangan yang dikembangkan oleh beberapa studi sebelumnya menunjukkan bahwa terdapat variasi perspektif dalam melihat baik faktor determinan maupun efektifitas ketahanan pangan. Mengingat fokus studi ini berusaha untuk memperoleh gambaran operasional ketahanan pangan agar dapat digunakan oleh pemangku kepentingan dalam pengambilan keputusan, maka hanya beberapa variabel yang akhirnya akan digunakan dalam studi ini dengan mempertimbangkan prinsip: (a) Prinsip Khusus, (b) Prinsip Operasional, dan (c) Prinsip Perbandingan. Prinsip ini bemanfaat menjadi penyaring terhadap indikator yang digunakan.

Tahap penyusunan indeks, diperlihatkan pada Gambar 1.

Seluruh data yang digunakan dalam indeks ini merupakan data sekunder. Data sekunder dalam penelitian ini diperoleh dari dokumen dan publikasi lembaga pemerintah yang terkait dengan ketahanan pangan.

Teknik Analisa Indeks. Indeks ini dianalisa dengan menggunakan beberapa teknik antara lain teknik transformasi data, teknik pembobotan dengan metode AHP serta penghitungan skor indeks. 


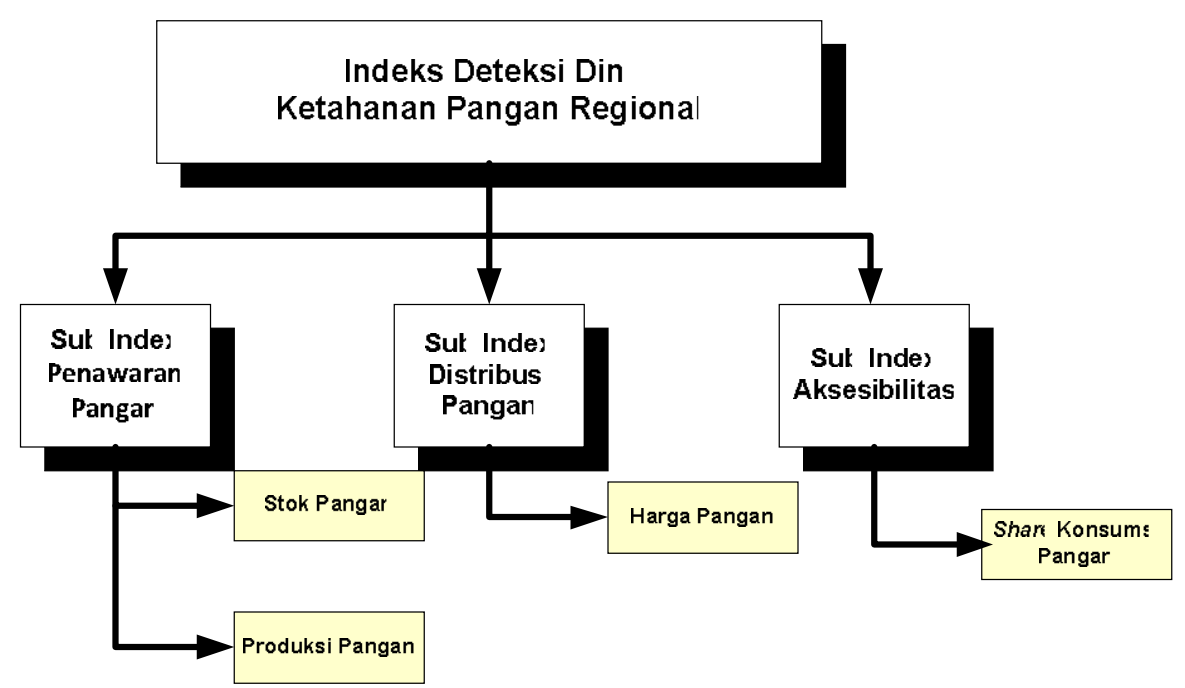

Gambar 1. Tahap Pengendalian Indeks

\section{HASIL DAN PEMBAHASAN}

\section{Hasil FGD dan AHP}

Dari hasil FGD, tim PIPW LPPM UNS jalur pengendalian barang kebutuhan pokok dan inflasi seperti pada Gambar 2.

Dari hasil FGD dihasilkan beberapa temuan penting yakni sebagai berikut:

- Secara umum para pemangku kepentingan setuju bahwa memang diperlukan sistem atau model baru pada era otonomi daerah dalam mendukung ketahanan pangan daerah, terutama setelah posisi Bulog berubah menjadi Perum.

- Sebagian besar pemangku kepentingan setuju bahwa TPID merupakan salah satu alternatif sistem ketahanan pangan daerah pada era dimana dalam rangka mengurangi informasi asimetris dalam pengendaliarn harga.

- Pendapat lain menyatakan bahwa bagaimanapun TPID hanyalah sebuah forum pengendalian harga saja, karena secara defacto TPID tidak bisa mengendalikan stok karena memang tidak mempunyai tugas dan fungsi seperti itu. Maka diberbagai daerah di Kabupaten Kota di Eks Karesidenan Surakarta mendirikan "Lumbung Desa" yang juga bertujuan menyimpan stok hasil panen atau mengusahakan gudanggudang penyimpanan yang dikelola oleh pemerintah daerah.

QE Journal | Vol.03 - No.02 June 2014 - 78 
Terutama para pemangku kepentingan yang berasal dari daeerah luar Kota Solo mempertanyakan bagaimana jika TPID juga dapat diterapkan di Kabupaten di daerah mereka. Karena selama ini TPID baru dibentuk di sebuah Kota yang ada Kantor Bank Indonesianya.

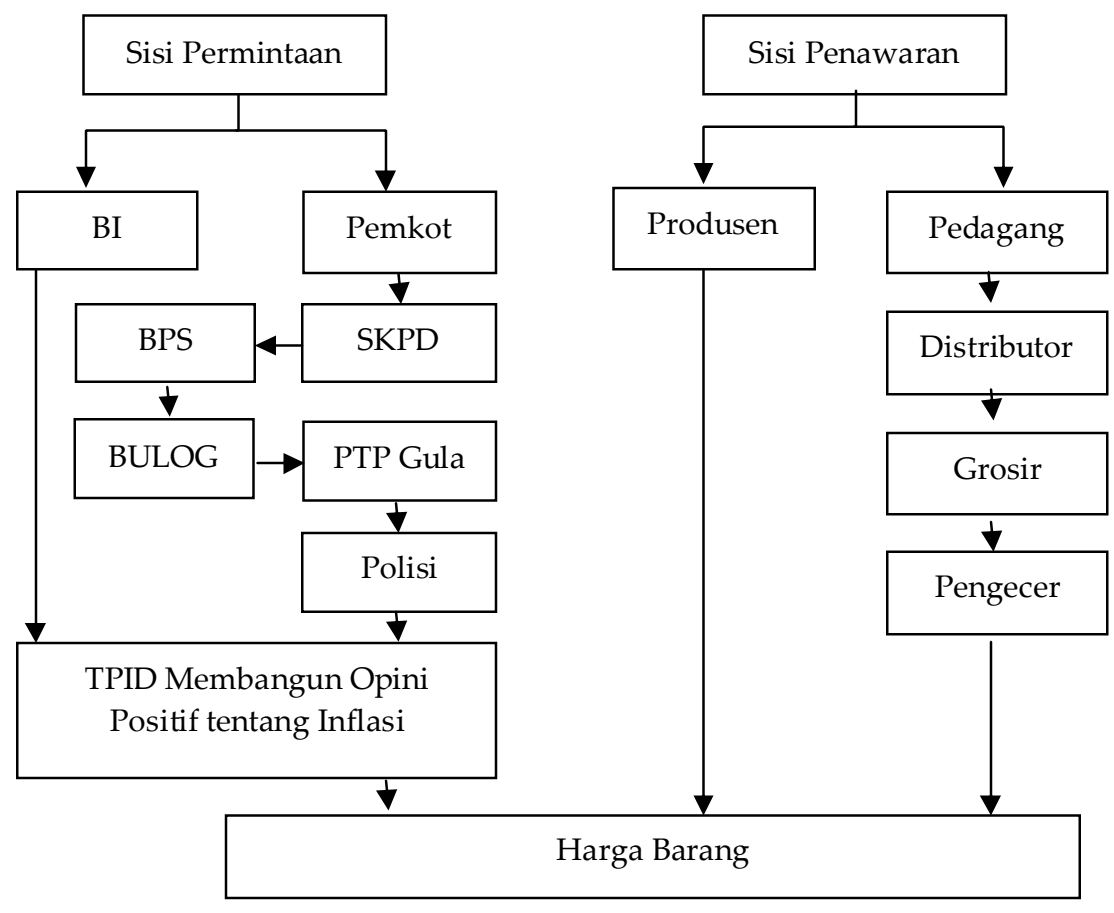

Gambar 2. Jalur Pengendalian Harga Barang Kebutuhan Pokok dan Inflasi

Hasil dari model AHP adalah akan diuraikan berikut ini. Dari pertanyaan tentang mana yang lebih penting dalam struktur pengendalian ketahanan pangan antara masalah harga, informasi dan stok. Ternyata sebagian besar pemangku kepentingan lebih memilih tentang harga $(0,376)$ yang disusul dengan masalah informasi $(0,345)$ dan terakhir adalah masalah stok $(0,279)$.

Tabel 1. Kriteria Struktur Ketahanan Pangan

\begin{tabular}{clcc}
\hline No. & Kriteria Struktur & Synthesize & Peringkat \\
\hline 1 & Harga & 0.376059 & I \\
2 & Informasi & 0.344552 & II \\
3 & Stok & 0.279388 & III \\
\hline \multicolumn{2}{l}{ Inconsistency index $=0.2292(<0.1$ atau $<10 \%)$}
\end{tabular}

QE Journal | Vol.03 - No.02 June 2014 - 79 


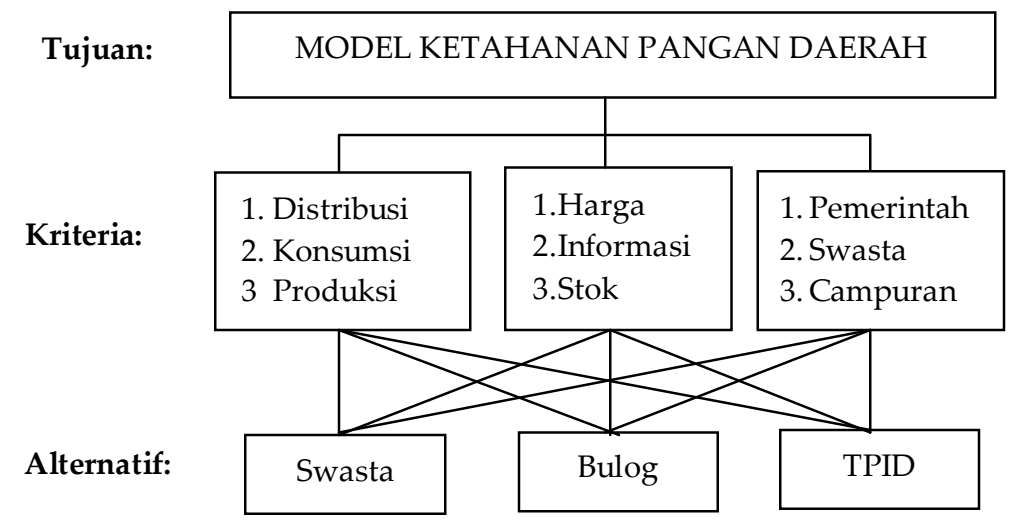

Gambar 3. Hirarki Model AHP Ketahanan Pangan Daerah

Demikian pula dalam pertanyaan tentang pentingnya fungsi antara distribusi, konusmsi dan produksi. Menurut para pemangku kepentingan yang paling penting adalah distribusi sebesar 0,598, sedangkan konsumsi 0,222, dan produksi 0,178.

Tabel 2. Kriteria Fungsi Ketahanan Pangan

\begin{tabular}{clcc}
\hline No. & Kriteria Fungsi & Synthesize & Peringkat \\
\hline 1 & Distribusi & 0.598820 & I \\
2 & Konsumsi & 0.222610 & II \\
3 & Produksi & 0.178571 & III \\
\hline
\end{tabular}

Inconsistency index $=0.1733(<0.1$ atau $<10 \%)$

Pertanyaan tentang penanggung jawab ketahanan pangan daerah. Sekitar 0,591 pemangku kepentingan melihat bahwa campuran antara pemerintah dan swasta adalah pihak yang bertanggungjawab terhadap ketahanan pangan daerah. Sementara yang memilih hanya pemerintah saja sebesar 0,285 , dan yang memilih swasta saja 0.123 . Ini menandakan para pemangku kepentingan berharap ada kerjasama antara pemerintah dan pihak swasta dalam mengendalikan ketahanan pangan daerah.

Tabel 3. Kriteria Penanggungjawab Ketahanan Pangan Daerah

\begin{tabular}{clcc}
\hline No. & Kriteria Penanggungjawab & Synthesize & Peringkat \\
\hline 1 & Campuran & 0.591541 & I \\
2 & Pemerintah & 0.285176 & II \\
3 & Swasta & 0.123283 & III \\
\hline
\end{tabular}

Inconsistency index $=0.0653(<0.1$ atau $<10 \%)$

Sementara itu, alternatif kelembagaan yang dipilih oleh pemangku kepentingan adalah bersaing ketat antara TPID dan Bulog. TPID didukung QE Journal | Vol.03 - No.02 June 2014 - 80 
oleh pemangku kepentingan sebesar 0,418, sementara itu Bulog didukung oleh 0,406, sedangkan SKPD hanya didukung 0,177. Ini menandakan bahwa TPID hanya menang tipis dibandingkan Bulog. Karena secara defakto TPID tidak menguasi stok, sementara Bulog menguasai stok dan mempunyai gudang serta pengalaman yang cukup lama. Temuan ini penting bahwa masih sebagian besar pemangku kepentingan berharap ada lembaga yang kuat dari sudut penyediaan stok dan juga mempunyai sistem pengendalian terhadap harga yang memadai seperti Bulog pada masa lalu. Namun dengan sistem yang baru pada era reformasi ini yang menyebabkan peranan Bulog menyempit, menyebabkan TPID menjadi salah satu alternative dalam ketahanan pangan daerah.

Tabel 4. Alternatif Kelembagaan

\begin{tabular}{clcc}
\hline No. & Alternatif Kelembagaan & Synthesize & Peringkat \\
\hline 1 & TPID & 0.417614 & I \\
2 & Bulog & 0.405613 & II \\
3 & SKPD & 0.176773 & III \\
\hline
\end{tabular}

Indeks EWS Ketahanan Pangan Daerah

Berdasarkan pengolahan data pola perkembangan tren indeks EWS di masing-masing daerah hampir sama. Pada awal tahun 2004 hingga 2008 nilai indeks EWS di daerah karesidenan Surakrta menunjukan angka yang terus meningkat. Pada tahun 2008 indeks EWS mencapai rata-rata 0,50 persen, dengan nilai indeks EWS tertinggi terjadi di Kabupaten Sragen yaitu sebesar 0,66 persen dan nilai indeks EWS terendah di Kota Surakarta yaitu sebesar 0,41, dengan rata-rata tren pertumbuhan dari tahun 2004-2008 sebesar 0,15 persen (Gambar 3).

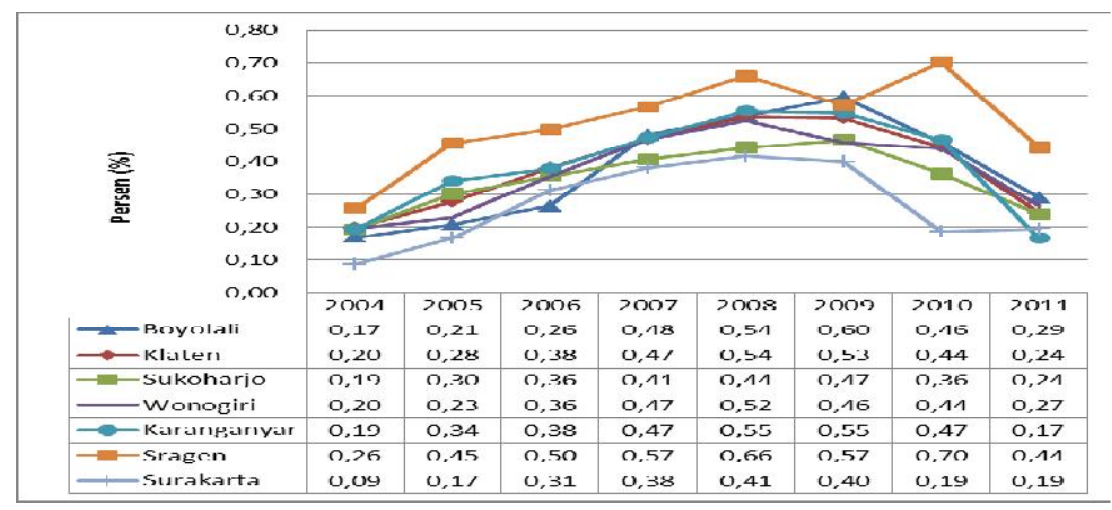

Gambar 3. Perkembangan Indeks EWS 


\section{SIMPULAN DAN SARAN}

\section{Simpulan}

Berdasarkan hasil FGD dan AHP para pemangku kepentingan bersepakat perlunya sistem ketahanan pangan daerah yang baru yang dapat melibatkan seluruh pemangku kepentingan baik unsur Pemerintah Kota/Kabupaten, Kantor Bank Indonesia, Bulog, Aparat Kepolisian dan pihak yang terkait lainya yang saat ini yakni lembaga yang sekarang ini disebut sebagai Tim Pengendali Inflasi Daerah (TPID).

TPID mempunyai keunggulan karena dapat merangkum seluruh pemangku kepentingan dalam melakukan rekomendasi dan membangun opini untuk memberikan informasi yang benar kepada masyarakat. Ini merupakan sebuah upaya yang lebih bijak agar sistem ketatalaksanaan ketahanan pangan daerah menjadi lebih berkesinambungan. Sementara itu, Indeks EWS ketahanan pangan menunjukkan bahwa daerah-daerah yang tidak mempunyai produksi tinggi dalam komoditi pangan memang mempunyai kerentanan lebih tinggi dibandingkan yang mempunyai produksi yang tinggi. Maka untuk Kabupaten/Kota yang seperti itu memerlukan dukungan kelembagaan seperti TPID sehingga proses penatalaksanaan menjadi lebih baik.

\section{Saran}

Studi ini merekomendasikan bahwa dalam rangka mendukung ketahanan pangan daerah maka di setiap Kab/Kota perlu didirikan TPID kendatipun tidak ada Kantor Bank Indonesia (KBI) di tempat itu. Oleh sebab itu perlu disosialisasikan kepada seluruh $\mathrm{Kab} / \mathrm{Kota}$ untuk menjajagi kemungkinan didirikan TPID di daerah-daerah tersebut. Dalam mengembangkan kinerjanya TPID perlu memperluas cakupan pemangku kepentingannya seperti usulan untuk memasukkan pihak swasta dalam tim ini, terutama para pedagang besar, sehingga memudahkan untuk memantau kenaikan harga barang di daerah tersebut.

\section{DAFTAR PUSTAKA}

Ali, Fachry, Imam Ahmad, Abdul Hamid, I Ketut Mardjana, Kholid Novianto, Al Chaidar, Nuryani Supriyadi, Wulandari Wijayanti, Siti Maryani. (1996). Beras, Koperasi dan Politik Orde Baru: Bustanil Arifin 70 Tahun. Jakarta: Pustaka Sinar Harapan. 
Arifin, Bustanul. (2004). Analisis Ekonomi Pertanian Indonesia. Jakarta: Kompas..

Behnassi, M, Draggan, S dan Yaya, S. (2011). Global Food Insecurity: Rethinking Agricultural and Rural Development Paradigm and Policy. London: Springer.

Ekananda, Mahyus (2009) Analisis Time Series dalam Ekonometrika. Bahan Kuliah Pasca Sarjana Ilmu Ekonomi,

Enders, Walter. (2004) Applied Econometric Time Series. Second Edition. New Jersey: John Wiley \& Sons

Falcon, W, P. \& Naylor, R. L.. (2005). Rethinking Food Security For The 21st Century. American Journal of Agricultural Economics. 87 (5), 11131127.

Fangquan, M. (2002). A Study on China's Grain and Food Security and Early Warning System. Working Paper, Institute of Information MOA, China.

Guha-Khasnobis, B, Acharya S.S, dan Davis, B. (2007). Food Security Indicators, Measurement, and the Impact of Trade Openness. New York: Oxford University Press.

Hakim, L, Suryono, Cahyadin, M (2010). Pemetaan Distribusi Komoditas Penyumbang Inflasi Regional Terbesar di Kota Solo dan Peranan TPID dalam Mendorong Ketahanan Pangan di Daerah. Ringksan Penelitian PPEP FE UNS dan KBI Solo.

Hakim, L. (2000). Perbandingan Peranan Jalur Kredit dan Suku Bunga dalam Mekanisme Transmisi Kebijakan Moneter 1990-1999. Tesis Program Pasca Sarjana Universitas Gadjah Mada: Yogyakarta.

Hariyadi, P.,D. Syah dan N, Andarwulan. (2003). Mewaspadai Jebakan Pangan di Indonesia. Jurusan Teknologi Pangan dan Gizi Fakultas Teknologi Pertanian IPB: Bogor.

Hayami, Yujiro, dan Vernon Ruttan. (1985) Agricultural Development: An International Perspectives. London: John Hopkins University Press

Hill, H. (1996). Transformasi Ekonomi Indonesia Sejak 1966: Sebuah Studi Kritis dan Komprehensif (terj), Tiara Wacana, Yogyakarta.

Khudori. (2004). Neoliberalisme Menumpas Petani: Menyingkap Kejahatan Industri Pangan. Yogyakarta: Resist Book.

Krishnamurti, B. (2003). Penganekaragaman Pangan: Pengalaman 40 Tahun dan Tantangan ke Depan. Artikel yang diunduh dari www.ekonomirakyat.org. 
Kuncoro, Mudrajad. 2002. Analisis Spasial dan Regional: Studi Aglomerasi dan Kluster Industri Indonesia. Yogyakarta: UPP AMP YKPN.

Mas'oed, Mohtar, 1989. Ekonomi dan Struktur Politik: Orde Baru 1966-1971, LP3ES, Jakarta.

Mears, Leon A. dan Sidik Moeljono. 1990. "Kebijakan Pangan", Anne Booth dan Peter McCawley (ed), Ekonomi Orde Baru. Jakarta: LP3ES.

Naylor, R. L. \& Falcon, W. P. (2010). Food Security in n Era of Economic Volatility. Population and Development Review 36(4):693 -723

Oey Beng To, 1991. Sejarah Kebijakan Moneter Indonesia Jilid 1 (1945-1958), Lembaga Pengembangan Perbankan Indonesia, Jakarta.

Prawiranegara, Sjafruddin. 1996. "Recollections of My Career", Bulletin of Indonesian Economic Studies, Vol. 23 No. 3, Desember.

Shaw, D.J (2007). World Food Security A History Since 1945. New York: Palgrave Macmillan.

Sjahrir. (1991). Analisis dan Metodologi Ekonomi Indonesia. Jakarta: Gramedia Pustaka Utama

Tambunan, Tulus,.(2001). Perekonomian Indonesia. Jakarta: Ghalia Indonesia

Timmer C. P. (2004a) Food Security and Economic Growth: an Asian Perspective Presented at Heinz W. Arndt Memorial Lecture, Canberra, November 22.

Timmer, C. P, Falcon, W.P, Pearson, S.R (1983). Food Policy Analysis. London: World Bank and The John Hopkins University Press.

Timmer, C. P. (2004b). Food Security in Indonesia: Current Challenges and the Long-Run Outlook. Center for Global Development, Working Paper Number 48 .

Timmer, C. P. (2007). The Structural Transformation and the Changing Role of Agriculture in Economic Development: Empirics and Implications. Presented at Wendt Lecture, American Enterprise Institute Washington, DC October 30.

Timmer, C.P. (2009) Supermarkets, Modern Supply Chains, and the Changing Food Policy Agenda. Center for Global Development Working Paper No.162

Timmer, C.P. (2011). Managing Price Volatility: Approaches at the Global, National, and Household Levels. Presented at Stanford Symposium Series on Global Food Policy and Food Security in the 21st Century. Center on Food Security and the Environment.

QE Journal | Vol.03 - No.02 June 2014 - 84 